\title{
Long-Term In Vitro Effectiveness of A Bioglass Desensitizing Agent Investigated Using Electrochemical Impedance Spectroscopy, Atomic Force Microscopy and Scanning Electron Microscopy
}

\author{
Shuya Shi ${ }^{1}, \mathbf{Q} \mathbf{W u}^{2}, \mathrm{YT} \mathrm{Xu}^{3}$ and Yaming Chen ${ }^{4^{*}}$ \\ ${ }^{1}$ Department of Stomatology, Affiliated Hospital of Jiangnan University, China \\ ${ }^{2}$ Department of Polyclinic, Affiliated hospital of Stomatology, Nanjing Medical University, Nanjing, China \\ ${ }^{3}$ Department of Endodontics, Suzhou Stomatological Hospital, China, \\ ${ }^{4}$ Institute of Stomatology, Nanjing Medical University, Nanjing, China
}

*Corresponding author: Yaming Chen, Department of Prosthetic Dentistry, Institute of Stomatology, Nanjing Medical University, 136 Hanzhong Road, Nanjing 210009 , China, Tel: +862585031832; Fax: +862586516414; E-mail: yaming_chen@yahoo.com

Received date: February 21, 2017; Accepted date: March 20, 2017; Published date: April 03, 2017

Copyright: ( 2017 Shi S, et al. This is an open-access article distributed under the terms of the Creative Commons Attribution License, which permits unrestricted use, distribution, and reproduction in any medium, provided the original author and source are credited.

\begin{abstract}
Objectives: To compare the long-term in vitro effectiveness of a newer desensitizing agent containing bioactive glass and two other commercial products employed for dentin hypersensitivity.

Methods: Fifty occlusal dentin disks from extracted sound human third molars were treated with $0.5 \mathrm{M}$ ethylenediaminetetraacetic acid for 2 min then randomly divided into five groups $(n=10)$. Specimens were brushed for 2 min twice daily with Actimins Paste (Group1), Lesening Super Desensitizing Toothpaste (Group2), Colgate Sensitive Pro-Relief Desensitising Polishing Paste (Group3) and distilled water (Group4) at 9:00 am and at 5:00 pm. Specimens in Group5 had no brushings. All specimens were immersed sequentially for $5 \mathrm{~min}$ into $\mathrm{coffee}(\mathrm{pH}=5.4)$ at 10:00 am and undiluted cola $(\mathrm{pH}=2.5)$ at 6:00 pm. Dentin permeability was measured weekly over one month using electrochemical impedance spectroscopy (EIS). Data were analyzed using two-way repeated measures ANOVA and post hoc LSD tests. Dentin microstructures were observed at one month by atomic force microscopy and scanning electron microscopy.
\end{abstract}

Results: The three desensitizing agents significantly reduced dentin permeability over one month. Post hoc LSD tests of the EIS values indicated that brushing with Actimins showed no significant difference from Colgate Sensitive $(P=0.32)$, and that both agents had significantly less permeability than Lesening $(P<0.05)$.

Conclusions: The three desensitizing agents were effective in occluding dentinal tubules and reducing permeability to varying extents over one month, with Actimins and Colgate Sensitive being the most effective. Actimins might be initially, a faster-working desensitizing agent.

Clinical significance: Actimins, a newer desensitizing agent containing bioactive glass, has the potential to relieve dentin hypersensitivity in the presence of long-term daily acidic beverage ingestion.

Keywords: Bioactive glass; Dentin hypersensitivity; Dentin permeability; Electrochemical impedance spectroscopy; Atomic force microscopy

\section{Introduction}

Dentin hypersensitivity (DH) has been characterized as a brief, sharp pain that occurs in response to thermal, evaporative, tactile, osmotic or chemical stimuli that may not be attributed to any form of dental defect or pathosis [1,2]. DH is closely bound up with the exposure of dentinal tubules as a result of enamel loss and/or gingival root surface exposure [1,2]. Many factors may contribute to the exposure of dentinal tubules, such as occlusal wear, abrasion, dietary erosion, parafunctional habits, gingival recession, aging, chronic periodontal disease, tooth abnormally positioned in the arch, periodontal surgery, incorrect tooth-brushing habits, root preparation and abfraction lesions [1-3].
The hydrodynamic theory was proposed as the basis for dentin hypersensitivity, which is caused by movement of fluid within open dentinal tubules [4]. Therefore, occlusion of the tubules should diminish fluid movements within them and the clinical symptoms of $\mathrm{DH}$, accordingly [5].

Many topically applied materials and treatments can produce promising short-term dentin desensitization [6]. And, if daily brushing with a desensitizing agent blocks exposed open dentinal tubules, this method should be an effective way to treat the common painful symptoms of DH. However, if the occlusion of the tubule orifices is only superficial, then daily tooth-brushing abrasion or exposure to acidic beverages may re-open the tubules, resulting in only a shortterm desensitizing effect $[7,8]$. Some in vitro studies have found that the risk for DH may increase with the presence of dietary acids [9]. Therefore, an ideal product for treating DH should not only reduce 
Citation: Shi S, Wu Q, Xu YT, Chen YM (2017) Long-Term In Vitro Effectiveness of A Bioglass Desensitizing Agent Investigated Using Electrochemical Impedance Spectroscopy, Atomic Force Microscopy and Scanning Electron Microscopy. Dentistry 7: 422. doi: $10.4172 / 2161-1122.1000422$

Page 2 of 8

dentin permeability, but also remain effective despite acid challenges and saliva immersion [10].

The application of a soluble bioactive glass with the potential to both occlude open dentinal tubules and to remineralize tooth structure offers a potential approach to the aforementioned problems. Bioactive glass was developed originally to stimulate the formation of new bone and was subsequently employed as a coating on orthopedic implants to promote adhesion between the implants and bone [11,12], and later to fill periodontal bone defects $[13,14]$. Recently, dentin desensitizing agents containing bioactive glass have been shown to have potential clinical efficacies for managing DH. A bioglass-containing toothpaste showed excellent in vitro dentinal tubule occlusive effects after brushing treatments and artificial saliva immersion [15], and the cytotoxicity testing of several bioactive glass pastes also indicated that they were highly biocompatible materials [16-18]. Although various desensitizing agents may be effective in reducing $\mathrm{DH}$ over a short period, little information is available on their long-term effectiveness.

The purpose of the present in vitro study is to compare the longterm effectiveness of a newer dentin desensitizing agent containing bioactive glass with two other commercial products used to treat dentin hypersensitivity. The null hypothesis proposed is that after one month of daily applications by brushing, the bioactive glass agent is no more effective for the occlusion of dentinal tubules than the other two commercial products.

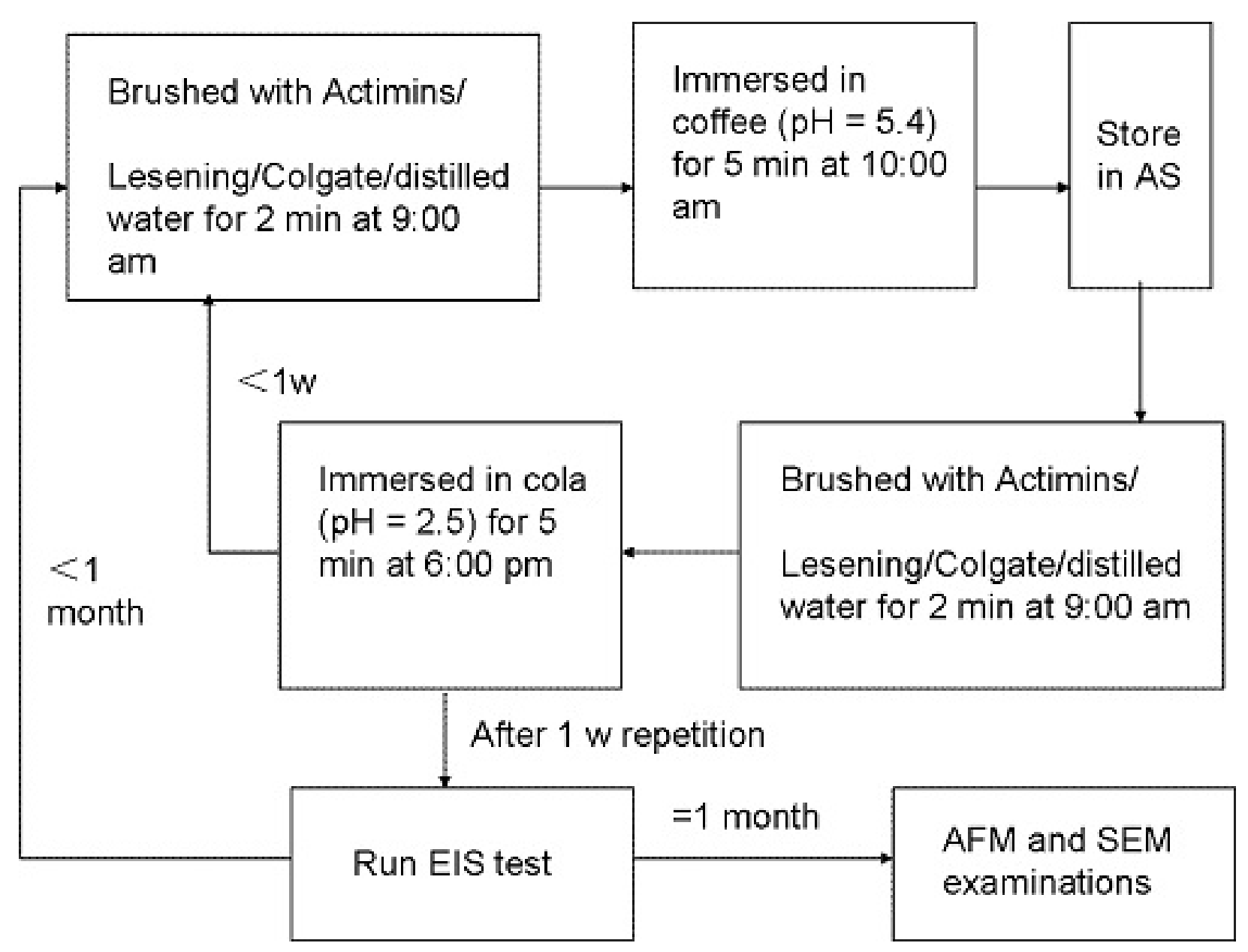

Figure 1: Flow chart of experimental procedures employed to compare the long-term in vitro desensitizing effectiveness among Actimins Paste, Lesening Super Desensitizing Toothpaste, Colgate Sensitive Pro-Relief Desensitising Polishing Paste and distilled water. AS: artificial saliva, EIS: electrochemical impedance spectroscopy, AFM: atomic force microscopy, SEM: scanning electron microscopy.

\section{Materials and Methods}

\section{Dentin specimen preparation}

Freshly extracted intact human third molars of Chinese adult patients, who were all living in the Nanjing non-fluoridated water supply region, were obtained from the affiliated Stomatological Hospital of Nanjing Medical University. The study was approved by the Ethics Committee of Nanjing Medical University, and the informed consent of the patients was obtained. All teeth were thoroughly cleaned, inspected carefully for any defects using a stereoscopic microscope at 10x magnification, and stored until required at $4^{\circ} \mathrm{C}$ in distilled water containing $0.5 \%$ thymol to inhibit microbial growth. Fifty selected teeth were sectioned perpendicular to their long axes 2.0-3.0 mm coronal to the buccal cemento-enamel junctions, to obtain single occlusal dentin disks with a thickness of approximately $1.0 \mathrm{~mm}$, using a water-cooled diamond saw (Isomet Low Speed Saw, Buehler 
Citation: Shi S, Wu Q, Xu YT, Chen YM (2017) Long-Term In Vitro Effectiveness of A Bioglass Desensitizing Agent Investigated Using Electrochemical Impedance Spectroscopy, Atomic Force Microscopy and Scanning Electron Microscopy. Dentistry 7: 422. doi: $10.4172 / 2161-1122.1000422$

Page 3 of 8

Ltd, Lake Bluff, IL, USA). No coronal enamel or pulp horn exposures were present in the specimens.

\begin{tabular}{|l|l|l|}
\hline Product & Manufacturer & Active ingredients \\
\hline Actimins Paste & $\begin{array}{l}\text { Datsing Bio-Tech Co. } \\
\text { Ltd, Beijing, China }\end{array}$ & $\begin{array}{l}\text { Calcium } \\
\text { phosphosilicate, silicon dioxide, } \\
\text { plant glycerin }\end{array}$ \\
\hline $\begin{array}{l}\text { Lesening Super } \\
\text { Desensitizing } \\
\text { Toothpaste }\end{array}$ & $\begin{array}{l}\text { Dencare Corp. Ltd, } \\
\text { Chongqing, China }\end{array}$ & $\begin{array}{l}\text { Potassium nitrate, strontium } \\
\text { chloride hexahydrate }\end{array}$ \\
\hline $\begin{array}{l}\text { Colgate Sensitive } \\
\text { Pro-Relief } \\
\begin{array}{l}\text { Desensitising } \\
\text { Polishing Paste }\end{array}\end{array}$ & $\begin{array}{l}\text { Colgate-Palmolive } \\
\text { Co., Guangzhou, } \\
\text { China } \quad \begin{array}{l}\text { Arginine, calcium carbonate, } \\
\text { sodium monofluorophosphate }\end{array}\end{array}$ \\
\hline
\end{tabular}

Table 1: Desensitization products employed, manufacturers and active ingredients.

\section{Experimental procedures}

The occlusal surfaces of all 50 dentin specimens were sanded with 600-grit silicon carbide paper for $30 \mathrm{~s}$ under continuous water irrigation before they were immersed into $0.5 \mathrm{M}$ ethylenediaminetetraacetic acid (EDTA) solution $(\mathrm{pH}=7.4)$ for 2 min to remove the standardized smear layer produced, and then gently rinsed with copious amounts of distilled water. Specimens were allocated using a table of random numbers to five groups $(n=10)$, and each brushed daily for 2 min at 9:00 am and at 5:00 pm with either Actimins Paste (Group 1), Lesening Super Desensitizing Toothpaste (Group 2), Colgate Sensitive Pro-Relief Desensitising Polishing Paste (Group 3) or distilled water (Group 4). Two electric tooth brushes with soft bristles (Colgate $360^{\circ}$, Colgate- Palmolive Co.) were employed, the first being replaced after 15 days. No brushing was used for the control specimens (Group 5). The manufacturers and active ingredients of the desensitizing agents used are shown in Table 1. After the 9:00 am brushings the specimens were immersed for $5 \mathrm{~min}$ in coffee $(\mathrm{pH}=5.4)$ at 10:00 am and, following the 5:00 pm brushings, the specimens were immersed for $5 \mathrm{~min}$ in undiluted cola drink $(\mathrm{pH}=2.5)$ at $6: 00 \mathrm{pm}$ (Figure 1). All specimens were placed into distilled water in an ultrasonic cleaner after the brushing treatments and acidic beverage immersions. The treatment cycle, using two beverages to simulate a common daily acid challenge, was repeated every day over one month. Between the treatment intervals, to simulate the oral environment, the specimens were stored in artificial saliva at $36.0^{\circ} \mathrm{C}$ (S.D. 1.0). The composition of the artificial saliva was $1.5 \mathrm{mM} / \mathrm{L} \mathrm{CaCl}_{2}, 50 \mathrm{mM} / \mathrm{L} \mathrm{KCl}$, $0.9 \mathrm{mM} / \mathrm{L}$ KH2PO 4 and $20 \mathrm{mM} / \mathrm{L}$ Tris $(\mathrm{pH}=7.4)$.

\section{Electrochemical impedance spectroscopy (EIS)}

EIS values for the dentin specimens were first measured after $2 \mathrm{~d}$ and then every $7 \mathrm{~d}$ during treatments using an Electrochemical Workstation (IM6, ZAHNER-Elektrik GmbH \& Co. KG, Kronach, Germany). The specimens were placed in separate split U-shaped chamber devices containing a pair of rubber O-rings ( $6 \mathrm{~mm}$ diameter), which resembled the hydraulic conductance device described and perfected by Pashley and coworkers [19]. A glassy carbon electrode was used for the working electrode (CHI104, CHI Instruments, Inc., Austin, TX, USA) and a platinum electrode was used for the counter electrode (CHI120, CHI Instruments, Inc.), each inserted into their respective half-cell. The occlusal surfaces of the specimens faced at the working electrode. $\mathrm{A} \mathrm{Ag} / \mathrm{AgCl}$ electrode was adopted for the reference electrode (CHI111, CHI Instruments, Inc.). Both half-cells were filled with $0.1 \mathrm{M} \mathrm{KCl}$ solution as the electrolyte. The dentin specimens were first soaked in the electrolyte for $2 \mathrm{~d}$ to expel any trapped air and to aid conductivity before the EIS measurements were made. The electrolyte was changed each EIS measurement. A sinusoidal voltage signal with an amplitude of $10 \mathrm{mV}$ was applied. EIS of the dentin specimens were measured at frequencies ranging from $0.1 \mathrm{~Hz}$ to $60 \mathrm{kHz}$ to obtain an impedance spectrum in the Nyquist (complex plane) plot. Factors affecting impedance $(\mathrm{k} \Omega)$ are the electrical resistance of the electrolyte solution, the resistance of the dentin specimens, and the resistance of the electrodes. Therefore, the dentin disk impedance $\mathrm{R}(\mathrm{d})$ equals the total impedance $\mathrm{R}(\mathrm{t})$ minus the impedance of the electrolyte $\mathrm{R}(\mathrm{e})$. And, at the frequency where the $\mathrm{Z}$-value (alternating current impedance vector) is the lowest, the $\mathrm{Z}$-value is close to that of $\mathrm{R}(\mathrm{t})$. $\mathrm{R}$ (e) was acquired by measuring the impedance of the $0.1 \mathrm{M} \mathrm{KCl}$ electrolyte alone, which was quite stable over 2-3 h.

\section{Atomic force microscopy (AFM)}

After one month of daily treatments, the dentin specimens were individually embedded in acrylic resin, polished sequentially with alumina polishing powders $(1.00 \mu \mathrm{m}, 0.30 \mu \mathrm{m}$ and $0.05 \mu \mathrm{m})$, and then placed into distilled water in an ultrasonic cleaner for $30 \mathrm{~min}$ to clean them before AFM examination. The scanning probe microscope (CSPM 5000, Ben Yuan Ltd, Beijing, China) employed was used with the tapping mode, in which the probe periodically touched the specimen surfaces to produce higher quality images with fewer artifacts [20,21]. An AFM probe (AC160TS-C2, Olympus Corp., Tokyo, Japan) was employed with a nominal resonant frequency of $\sim 300 \mathrm{kHz}$, and a nominal spring force constant of $\sim 42 \mathrm{~N} / \mathrm{m}$. Images were obtained using a slow scan rate of $\sim 1.5 \mathrm{~Hz}$, at a chosen resolution of $512 \times 512$ pixels. Images could be obtained with a maximum vertical resolution of $0.1 \mathrm{~nm}$ and a lateral resolution of $0.2 \mathrm{~nm}$. Quantitative information regarding the dentinal tubule diameters was obtained using the AMF image data analysis software provided by the manufacturer.

\section{Scanning electron microscopy (SEM)}

After one month of daily treatments, the same specimens were first rinsed with copious distilled water, dried in a desiccator and then sputter-coated with gold in a vacuum to aid conductivity before the dentin surfaces were examined using SEM. Micrographs of the dentin surfaces were obtained using a scanning electron microscope (JSM6300, JEOL, Tokyo, Japan) at an accelerating beam voltage of 20 $\mathrm{kV}$.

\section{Statistical analysis}

Statistical analysis of the ETS data was performed using the Statistical Package for the Social Sciences V17.0 software (SPSS Inc., Chicago, IL, USA). After confirming the equality of the variances using Levene's test, any significant statistical differences among the groups for dentin impedance were determined by two-way repeated measures ANOVA and Fisher's post hoc Least Significant Difference (LSD) tests. The probability level for statistical significance was set at $\alpha=0.05$. 
Citation: Shi S, Wu Q, Xu YT, Chen YM (2017) Long-Term In Vitro Effectiveness of A Bioglass Desensitizing Agent Investigated Using Electrochemical Impedance Spectroscopy, Atomic Force Microscopy and Scanning Electron Microscopy. Dentistry 7: 422. doi: $10.4172 / 2161-1122.1000422$

Page 4 of 8

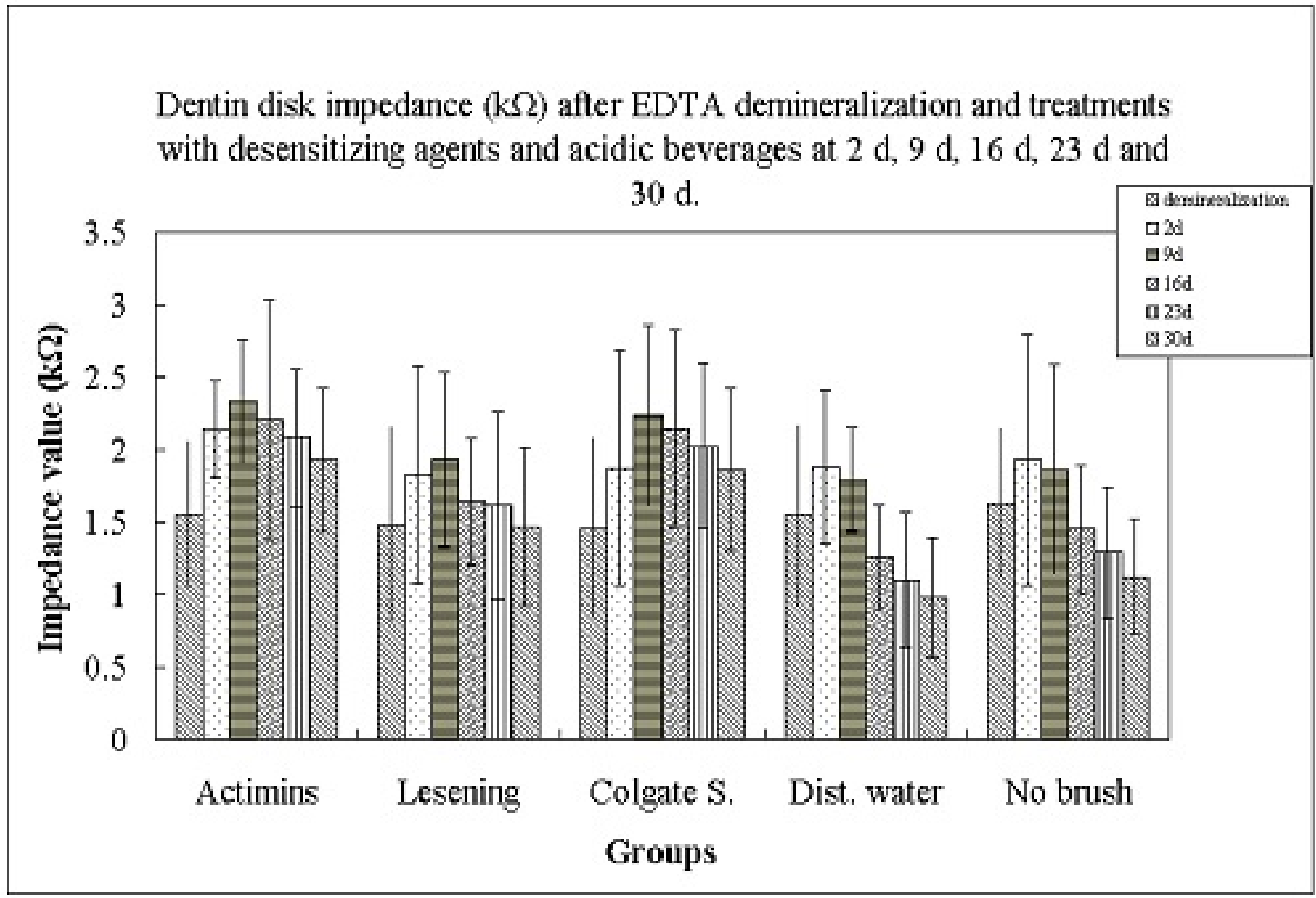

Figure 2: Histogram of Means (Standard Deviations- vertical lines) for electrochemical impedance spectroscopy data after dentin demineralization and treatments with desensitizing agents and acidic beverages for 2, 9, 16, 23 and 30 days.

\section{Results}

\section{EIS evaluation}

The results for the dentin disk impedances $(\mathrm{k} \Omega)$ after demineralization and treatments with desensitizing agents and acidic beverages are shown in Table 2 and illustrated graphically in Figure 2. Two-way repeated measures ANOVA revealed significant main effects for time $(\mathrm{F}=7.42 ; \mathrm{P}<0.05)$ and group $(\mathrm{F}=12.07 ; \mathrm{P}<0.05)$. Post hoc LSD testing indicated that brushing with Actimins significantly reduced dentin permeability compared to all other treatments $(\mathrm{P}<0.05)$ except Colgate Sensitive Pro-Relief $(\mathrm{P}=0.32)$. Brushing with Actimins produced the highest EIS values among all groups at all time periods. Brushing with distilled water showed lower EIS values at all time periods than for no brushing, but the differences were not significant (P 0.25). Although brushing with Lesening Super Desensitizing generally showed higher EIS values at all time periods than for no brushing, the differences again were not significant $(\mathrm{P}=0.29)$.

\section{AFM evaluation}

Figure 3 shows selected AFM micrographs of topographical representations from Groups 1, 2 and 3 after one month of desensitizing treatments. Granular intertubular surface debris is present on all specimens, and narrowing of the dentinal tubule orifices is most obvious for Group 1. The mean diameters of the dentinal tubule orifices in Group 1 (Actimins), Group 2 (Lesening Super Desensitizing) and Group 3 (Colgate Sensitive Pro-Relief) were approximately 817.19 (S.D. 156.47) $\mu \mathrm{m}, 1,231.97$ (277.32) $\mu \mathrm{m}$ and $944.71(230.84) \mu \mathrm{m}$, respectively. The mean diameter of the dentinal tubule orifices for Lesening was significantly larger than the mean diameters for either Actimins $(\mathrm{P}<0.01)$ or Colgate Sensitive $(\mathrm{P}<0.05)$, whose mean diameters were statistically, similar $(\mathrm{P}>0.05)$.

\section{SEM evaluation}

Figure 4 shows selected SEM micrographs of topographical representations from all groups after one month of different treatments. Brushing with Actimins $(A, B)$ resulted in a fairly homogenous granular dentin surface having the appearance of an artificial smear layer and showing relatively few open dentinal tubules with significantly reduced diameters and the most pronounced tubule orifice occlusions. Brushing with Lesening Super Desensitizing (C,D) and with Colgate Sensitive Pro-Relief (E,F) created a reduced prominence of the dentinal tubules, with reduced tubule orifice diameters and small granular deposits on the dentin surfaces and partially occluding the orifices, which effect appeared to be more slightly more pronounced for Colgate Sensitive. Brushing with distilled water only $(\mathrm{G}, \mathrm{H})$ and the no-brushing controls $(\mathrm{I}, \mathrm{J})$ showed large open dentinal tubule orifices, with slightly more dentin debris present on the dentin surfaces and pushed into the tubule orifices in the distilled water specimens. 
Citation: Shi S, Wu Q, Xu YT, Chen YM (2017) Long-Term In Vitro Effectiveness of A Bioglass Desensitizing Agent Investigated Using Electrochemical Impedance Spectroscopy, Atomic Force Microscopy and Scanning Electron Microscopy. Dentistry 7: 422. doi: $10.4172 / 2161-1122.1000422$

Page 5 of 8
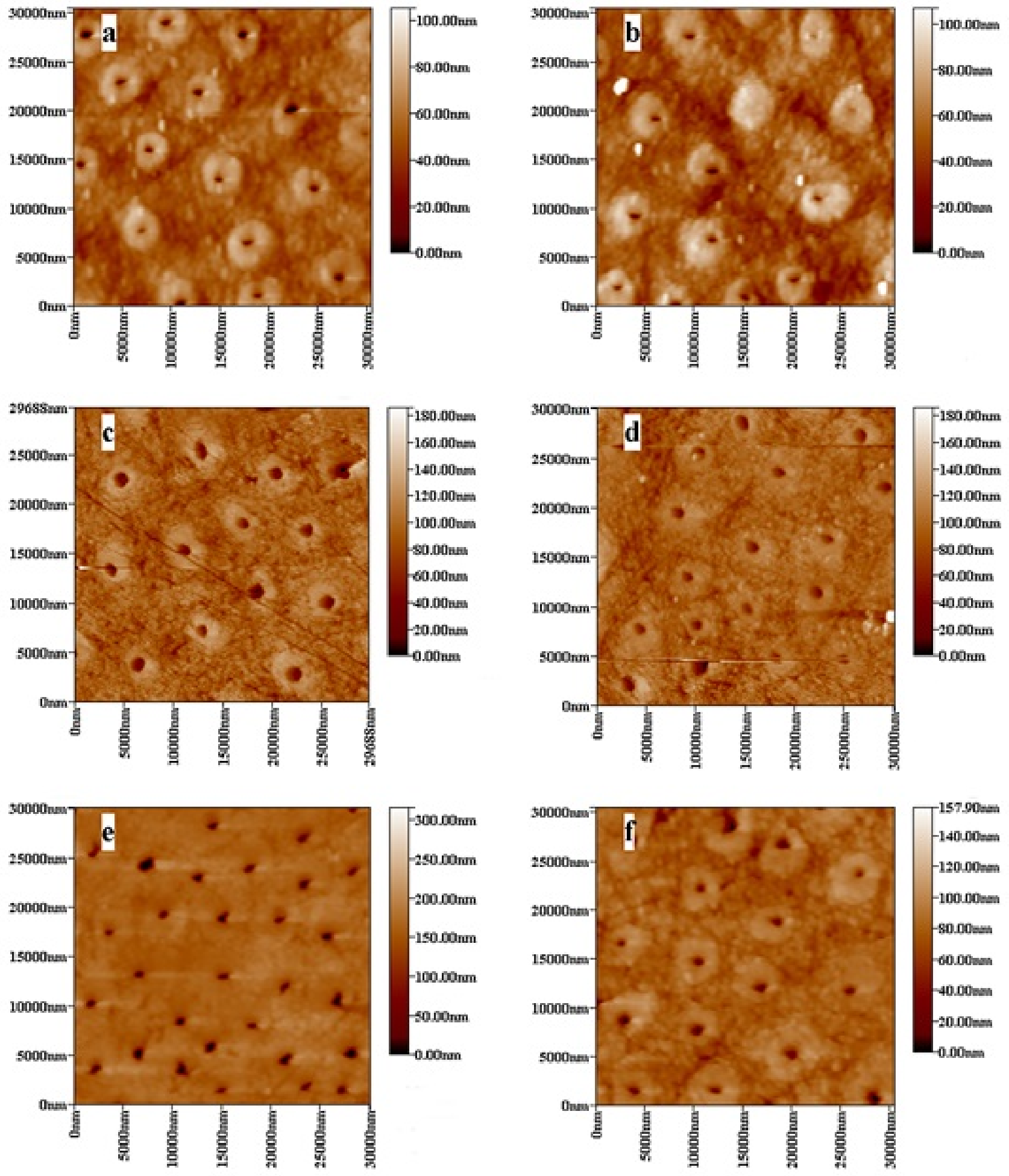

Figure 3: Tapping mode AFM micrographs of specimen surfaces in Group 1 (A, B), Group 2 (C, D) and Group 3 (E, F) after one month of desensitizing treatments. The mean diameters of the dentinal tubule orifices became progressively wider from Group 1 (Actimins), to Group 3 (Colgate Sensitive Pro-Relief), to Group 2 (Lesening Super Desensitizing). The two micrographs in each group were chosen from two individual samples. Note: arrows show some completely occluded dentinal tubule orifices in (B). (Original image sizes $30 \mu \mathrm{m} \times 30 \mu \mathrm{m}$ ). 
Citation: Shi S, Wu Q, Xu YT, Chen YM (2017) Long-Term In Vitro Effectiveness of A Bioglass Desensitizing Agent Investigated Using Electrochemical Impedance Spectroscopy, Atomic Force Microscopy and Scanning Electron Microscopy. Dentistry 7: 422. doi: $10.4172 / 2161-1122.1000422$

Page 6 of 8

\begin{tabular}{|c|c|c|c|c|c|c|}
\hline $\begin{array}{l}\text { Treatment } \\
\text { ( } n=10 / \text { grp) }\end{array}$ & EDTA & 2 days & 9 days & 16 days & 23 days & 30 days \\
\hline Group 1 & $\begin{array}{l}1.55 \\
(0.51)^{\mathrm{a}}\end{array}$ & $\begin{array}{l}2.14 \\
(0.34)^{\mathrm{a}}\end{array}$ & $\begin{array}{l}2.33 \\
(0.43)^{\mathrm{a}}\end{array}$ & $\begin{array}{l}2.20 \\
(0.82)^{\mathrm{a}}\end{array}$ & $\begin{array}{l}2.09 \\
(0.47)^{\mathrm{a}}\end{array}$ & $\begin{array}{l}1.93 \\
(0.49)^{\mathrm{a}}\end{array}$ \\
\hline \multicolumn{7}{|l|}{ Actimins } \\
\hline Group 2 & $\begin{array}{l}1.48 \\
(0.68)^{\mathrm{a}}\end{array}$ & $\begin{array}{l}1.83 \\
(0.75)^{b}\end{array}$ & $\begin{array}{l}1.93 \\
(0.61)^{b}\end{array}$ & $\begin{array}{l}1.64 \\
(0.44)^{\mathrm{b}}\end{array}$ & $\begin{array}{l}1.62 \\
(0.65)^{a, b}\end{array}$ & $\begin{array}{l}1.46 \\
(0.54)^{\mathrm{b}}\end{array}$ \\
\hline \multicolumn{7}{|l|}{ Lesening } \\
\hline Group 3 & $\begin{array}{l}1.46 \\
(0.63)^{\mathrm{a}}\end{array}$ & $\begin{array}{l}1.87 \\
(0.81)^{b}\end{array}$ & $\begin{array}{l}2.24 \\
(0.62)^{a}\end{array}$ & $\begin{array}{l}2.14 \\
(0.68)^{a}\end{array}$ & $\begin{array}{l}2.02 \\
(0.57)^{a}\end{array}$ & $\begin{array}{l}1.86 \\
(0.56)^{a, b}\end{array}$ \\
\hline \multicolumn{7}{|l|}{ Colgate S. } \\
\hline Group4 & $\begin{array}{l}1.55 \\
(0.63)^{\mathrm{a}}\end{array}$ & $\begin{array}{l}1.88 \\
(0.53)^{b}\end{array}$ & $\begin{array}{l}1.79 \\
(0.36)^{b}\end{array}$ & $\begin{array}{l}1.26 \\
(0.36)^{b}\end{array}$ & $\begin{array}{l}1.10 \\
(0.46)^{c}\end{array}$ & $\begin{array}{l}0.98 \\
(0.41)^{c}\end{array}$ \\
\hline \multicolumn{7}{|l|}{ Dist. water } \\
\hline Group 5 & $\begin{array}{l}1.63 \\
(0.52)^{\mathrm{a}}\end{array}$ & $\begin{array}{l}1.93 \\
(0.86)^{b}\end{array}$ & $\begin{array}{l}1.86 \\
(0.72)^{b}\end{array}$ & $\begin{array}{l}1.46 \\
(0.44)^{b}\end{array}$ & $\begin{array}{l}1.29 \\
(0.45)^{b, c}\end{array}$ & $\begin{array}{l}1.12 \\
(0.39)^{b, c}\end{array}$ \\
\hline No brush. & & & & & & \\
\hline
\end{tabular}

Table 2: Dentin disk impedance (Mean, Standard Deviation) after EDTA demineralization and treatments with desensitizing agents and acidic beverages at $2,9,16,23$ and 30 days.

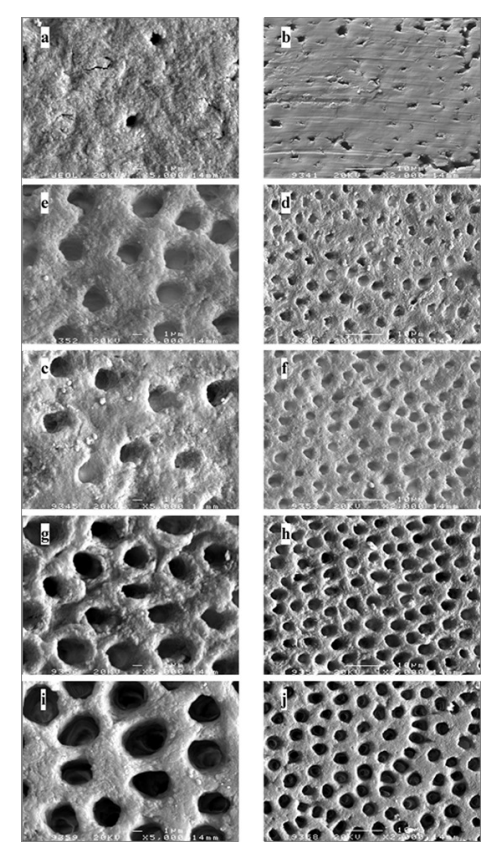

Figure 4: SEM micrographs of the dentin surfaces after one month of desensitizing treatments and being exposed to brushing and acidic solutions. Actimins (A, B), Lesening Super Desensitizing (C, D), Colgate Sensitive Pro-Relief (E, F), distilled water (G, H) and no-brushing controls (I, J). The two micrographs in each group were chosen from two individual samples. (Original magnifications left side 5000X, and right side 2000X).

\section{Discussion}

Treatments for DH may be classified into chemical and physical methods [22]. Chemical agents have included strontium chloride, sodium fluoride, formalin solution [23], ferric oxalate [24], calcium hydroxide, stannous hydroxide, calcium oxalate, ferric phosphate [25] and potassium nitrate [26]. Physical methods have included the use of a fluoride-releasing resin [27] and lasers [28-30]. All these treatments have produced promising yet relatively short-lived therapeutic effects. After daily tooth brushing and mastication, or following their immersion in artificial saliva and acidic beverages, these agents were gradually abraded or solubilized and eventually lost their dentinal tubule occlusive effect [6]. Therefore, when appraising any treatment method employed for treating $\mathrm{DH}$, its long-time effectiveness must be evaluated. Based the hydrodynamic theory for pulpal pain $[4,31]$, attention has focused more recently on the tubular occlusive action and dentin remineralizing ability of bioactive glasses.

EIS is a non-destructive and sensitive technique for evaluating the patency of dentinal tubules. EIS has been used also to assess the effects of acids on dentin permeability [19,32], the effectiveness of resindentin bonds [33], and the microleakage of resin composite restorations [34] and temporary restorations after root canal therapy [35]. Measurements of dentin permeability using EIS require the penetration of an electrolyte into the dentin specimens to make them conductive. The conductive properties and, hence, the impedance spectra obtained are characterized by the microstructure of the specimens. In the present study, the electrochemical impedance of a dentin disk specimen, at various alternating current frequencies, depends on the differences in potentials between the two half-cells on each side of the dentin disk and on the electrical current through the dentinal tubules [19]. Occlusion of the dentinal tubules leads to a decrease in hydraulic conductance (less fluid shift) and an increase in resistance to electrical currents (less ionic movement). The value will be low when the tubules are patent and high when the tubules are occluded [19].

AFM provides not only topographical images but accurate quantitative information (dimensions, profile, roughness and periodicity) of the specimen surfaces [36]. For investigations of biological specimens, the tapping mode is preferred to avoid surface damage caused by probing friction [37]. Because the fine polishing powders used in the present study were of small diameters $(1.00 \mu \mathrm{m}$, $0.30 \mu \mathrm{m}$ and $0.05 \mu \mathrm{m}$ ), and the mean diameter of the dentinal tubules from human third molars in young adults was reported to be approximately $1.21(0.08) \mu \mathrm{m}$ [38], it was critical to place the specimens in an ultrasonic cleaner for $30 \mathrm{~min}$ before commencing the AFM observations. By comparison with SEM, there are reduced artifacts, and the physical or chemical fixations and coating of the specimen surfaces by sputtering for better contrast and conductivity are not necessary.

The results from EIS showed that Actimins Paste containing bioactive glass created the lowest dentin permeability among the groups tested (Table 2). As a biocompatible material, bioactive glass has a high surface reactivity in physiological systems that can deposit hydroxycarbonate apatite, a mineral chemically similar to natural tooth mineral. Such reactivity happens through a series of interdependent sequential reactions. The gradual dissolution of bioglass occurs by hydrolysis of the silicate network [11]. Free silicate ions spontaneously adsorb onto the dentin surface and undergo condensation to form surface functional silanol groups ( $\mathrm{Si}-\mathrm{OH})$, which act as heterogenic nucleation sites. Positively charged calcium ions are 
Citation: Shi S, Wu Q, Xu YT, Chen YM (2017) Long-Term In Vitro Effectiveness of A Bioglass Desensitizing Agent Investigated Using Electrochemical Impedance Spectroscopy, Atomic Force Microscopy and Scanning Electron Microscopy. Dentistry 7: 422. doi: $10.4172 / 2161-1122.1000422$

Page 7 of 8

then adsorbed as a consequence of electrostatic attractions with negatively charged $\equiv \mathrm{Si}-\mathrm{O}$ - units, formed by dissociation of the $\mathrm{Si}-\mathrm{OH}$ groups. This reaction produces a positively charged calcium silicate, which interacts with the negatively charged phosphate ions in the surrounding fluid to form a calcium phosphate structure [39].

At 2 days, the EIS values for all specimens had an upward tendency, of which Actimins was the most pronounced, implying that brushing with Actimins may relieve the symptoms of $\mathrm{DH}$ more rapidly than Lesening and Colgate Sensitive (Table 2). The surface deposits from brushing with Actimins were mostly retained within the dentinal tubules, largely resisting brushing and the dissolution effects of artificial saliva immersion, distilled water rinsing, and subsequent erosive challenges by coffee and undiluted cola. Such resistance is very important for reducing the permeability of the dentin and to maintain a sustained effect in reducing $\mathrm{DH}$.

Lesening contains potassium nitrate and strontium chloride, which have been used extensively in dentifrices to alleviate the symptoms of $\mathrm{DH}$. Potassium ions are able to reduce nerve excitability in hypersensitive teeth. And, in vitro, strontium was associated with the improved mineral density of demineralized dentin [40] and also acted synergistically with fluoride [41]. However, in the present study, brushing with Lesening was generally no more effective in reducing dentin permeability than was no brushing $(\mathrm{P}=0.29)$.

Colgate Sensitive toothpaste containing $8.0 \%$ arginine and 1450 ppm fluoride has demonstrated remarkable clinical reductions in $\mathrm{DH}$ [42]. The Pro-Argin formula dentifrice was highly effective in occluding dentinal tubules, and the arginine-containing dentin plugs could resist an acid challenge [43]. In the present in vitro study, Actimins and Colgate Sensitive had low and similar dentin permeability results $(\mathrm{P}=0.32)$.

After the initial EDTA challenge, brushing with distilled water and even no brushing produced short-term reductions in dentin permeability following the artificial saliva immersions, which were then followed by increases in dentin permeability (Table 2). A previous study found that brushing with distilled water would leave some dentin smear debris in the tubules [15]. And, as in the present study, it was reported that brushing after undiluted cola drink immersions also resulted in some dentin smear debris in the tubules and that 'No significant morphological differences were observed from samples without toothbrushing' [9]. Artificial saliva is able to solubilize some particles from dentinal tubules to make the dentin more permeable [10]. However, during remineralization in artificial saliva, mineral salts may create crystal precipitates on the dentin surface, leading to a reduction in permeability [7]. Apart from the brushing treatments, the resulting permeability of the dentin would also reflect the demineralization and remineralization cycle treatments.

The presence of pulpal pressure in vital teeth may be an additional influence on the long-term maintenance by desensitizing agents of dentinal tubule occlusion. Therefore, in situ and in vivo studies are necessary to confirm the findings of this in vitro study.

\section{Conclusions}

The three tested tooth desensitizing agents showed long-term decreased permeability of occlusal dentin specimens to varying degrees. Material deposited in the dentinal tubules during daily tooth brushings largely resisted concomitant acid challenges and artificial saliva immersions over one month. Actimins Paste reduced dentin permeability rapidly, and had a larger but not significantly greater long-term reduction than Colgate Sensitive $(\mathrm{P}=0.32)$. Both agents showed significantly more reductions in permeability than Lesening $(\mathrm{P}<0.05)$. Therefore, the null hypothesis was accepted only for Colgate Sensitive.

\section{Acknowledgements}

The authors would like to thank Professors Zhiping Bai and Jianwei Zhao from Nanjing University for assisting with the EIS and the AFM measurements, respectively. We also appreciated the financial support received from A Project Funded by the Priority Academic Program Development of Jiangsu Higher Education Institutions, Project No.: 2011-137, and Research into dentin hypersensitivity and bioactive glass, Project No.: 22011-001.

\section{References}

1. Addy M (2000) Dentine hypersensitivity: definition, prevalence, distribution and aetiology. In: Addy M, Embery G, Edgar W, Orchardson R (eds.) Tooth wear and sensitivity. Martin-Dunitz, London: 239-248.

2. Addy M, Dowell P (1983) Dentine hypersensitivity - review. Clinical and in vitro evaluation of treatment agents. J Clin Periodontol 10: 351-363.

3. Pashley DH (1990) Mechanisms of dentine sensitivity. Dent Clin N Am 34: 449-473.

4. Brännström M, Linden LA, Johnson G (1968) Movement of dentinal and pulpal fluid caused by clinical procedures. J Dent Res 47: 679-682.

5. Pashley DH (1986) Dentine permeability, dentine sensitivity and treatment through tubule occlusion. J Endod 12: 465-474.

6. Lee BS, Chang CW, Chen WP, Lan WH, Lin CP (2005) In vitro study of dentin hypersensitivity treated by Nd: YAP laser and bioglass. Dent Mater 21: 511-519.

7. Suge T, Kawasaki A, Ishikawa K, Matsuo T, Ebesu S (2008) Ammonium hexafluorosilicate elicits calcium phosphate precipitation and shows continuous dentine tubule occlusion. Dent Mater 24: 192-198.

8. Sauro S, Watson TF, Thompson I (2010) Dentine desensitization induced by prophylactic and air-polishing procedures: $\mathrm{An}$ in vitro dentine permeability and confocal microscopy study. J Dent 38: 411-422.

9. Prati C, Montebugnoli L, Suppa P, Valdrè G, Mongiorgi R (2003) Permeability and morphology of dentine after erosion induced by acidic drinks. J Periodontol 74: 428-436.

10. Gandolfi MG, Silvia F, Pashley DH, Gasparotto G, Cario P (2008) Calcium silicate coating derived from Portland cement as treatment for hypersensitive dentine. J Dent 36: 565-578.

11. Hench LL, Paschall HA (1973) Direct chemical bond of bioactive glassceramic materials to bone and muscle. J Biomed Mater Res 7: 25-42.

12. Hench LL (2006) The story of bioglass. J Mater Sci: Mater Med 17: 967-978.

13. Wilson J, Low SB (1992) Bioactive ceramics for periodontal treatment: comparative studies in the patus monkey. J Appl Biomater 3: 123-129.

14. Lovelace TB, Melloning JT, Meffert RM, Jones AA, Nummikoski PV (1998) Clinical evaluation of bioactive glass in the treatment of periodontal osseous defects in humans. J Periodontol 69: 1027-1035.

15. Wang Z, Sa Y, Sauro S, Chen H, Xing W, et al. (2010) Effect of desensitising toothpastes on dentinal tubule occlusion: A dentine permeability measurement and SEM in vitro study. J Dent 38: 400-410.

16. Kuo TC, Lee BS, Kang SH, Lin FH, Lin CP (2007) Cytotoxicity of DPbioglass paste used for treatment of dentin hypersensitivity. J Endod 33: 451-454.

17. Bakry AS, Tamura Y, Otsuki M, Kasugai S, Ohya K (2011) Cytotoxicity of $45 \mathrm{~S} 5$ bioglass paste used for dentine hypersensitivity treatment. J Dent 39: 599-603.

18. Wilson J, Pigotl GH, Schoen FJ, Hench LL (1981) Toxicology and biocompatibility of bioglasses. J Biomed Mater Res 15: 805-817. 
Citation: Shi S, Wu Q, Xu YT, Chen YM (2017) Long-Term In Vitro Effectiveness of A Bioglass Desensitizing Agent Investigated Using Electrochemical Impedance Spectroscopy, Atomic Force Microscopy and Scanning Electron Microscopy. Dentistry 7: 422. doi: $10.4172 / 2161-1122.1000422$

Page 8 of 8

19. Pradelle-Plasse N, Wenger F, Colon P (2002) Effect of conditioners on dentine permeability using an impedance method. J Dent 30:251-257

20. Eliades G, Vougiouklakis G, Palaghias G (1999) Effect of dentine primers on the morphology, molecular composition and collagen conformation of acid-demineralized dentine in situ. Dent Mater 15: 310-317.

21. Silikas N, Watts DC, England KER, Jandt KD (1999) Surface fine structure of treated dentine investigated with tapping mode atomic force microscopy (TMAFM). J Dent 27: 137-144.

22. Scherman A, Jacobsen PL (1992) Managing dentine hypersensitivity: what treatment to recommend to patients. J Am Dent Assoc 123: 57-61.

23. Kishore A, Mehrotra KK, Saimbi CS (2002) Effectiveness of desensitizing agents. J Endod 28:.34-35.

24. Gillam DG, Khan N, Mordan NJ, Barber PM (1999) Scanning electron microscopy (SEM) investigation of selected desensitizing agents in the dentine disc model. Endod \& Dent Traumatol 15: 198-204.

25. Jain P, Vargas MA, Denehy GE, Boyer DB (1997) Dentine desensitizing agents: SEM and X-ray microanalysis assessment. Am J Dent 10:.21-26.

26. Nagata T, Ishida H, Shinohara H, Nishikawa S, Wakano Y, et al. (1994) Clinical evaluation of a potassium nitrate dentifrice for the treatment of dentinal hypersensitivity. J Clin Periodontol 21: 217-221.

27. Tavares M, Depaola PF, Soparkar P (1994) Using a fluoride-releasing resin to reduce cervical sensitivity. J Am Dent Assoc 125: 1337-1342

28. Lan WH, Liu HC (1994) Sealing of human dentinal tubules by Nd: YAG laser. J Dent Res 73:.1684-1689.

29. Zhang C, Matsumoto K, Kimura Y, Harashima T, Takeda FH, et al. (1998) Effect of $\mathrm{CO} 2$ laser in treatment of cervical dentinal hypersensitivity. J Endod 24: 595-597.

30. Schwarz F, Arweiler N, Georg T, Reich E (2002) Desensitizing effects of an Er: YAG laser on hypersensitive dentine. A controlled, prospective clinical study. J Clin Periodontol 29: 211-215.

31. Brännström M, Garberoglio R (1972) The dentinal tubules and the odontoblast processes: a scanning electron microscopic study. Acta Odontolog Scand 30: 291-311.

32. Xu Z, Neoh KG, Kishen A (2008) Monitoring acid-demineralization of human dentine by electrochemical impedance spectroscopy (EIS). J Dent 36: 1005-1012.
33. Sword J, Pashley DH, Foulger S, Tay FR, Rodgers R (2008) Use of electrochemical impedance spectroscopy to evaluate resin-dentine bonds. J Biomed Mater Res Part B Appl Biomater 84: 468-477.

34. Pradelle-Plasse N, Wenger F, Picard B, Colon P (2004) Evaluation of microleakage of composite resin restorations by an electrochemical technique: the impedance methodology. Dent Mater 20: 425-434.

35. Jacquot BM, Panighi MM, Steinmetz P, G'sell C (1996) Evaluation of temporary restorations' microleakage by means of electrochemical impedance measurements. J Endod 22: 586-589.

36. Sanches RP, Otani C, Damião AJ, Miyakawa W (2009) AFM characterization of bovine enamel and dentine after acid-etching. Micron 40: 502-506.

37. Kubinek R, Zapletalová Z, Vújtek M, Novotný R, Kolárová H, et al. (2007) Sealing of open dentinal tubules by laser irradiation: AFM and SEM observations of dentine surfaces. J Mol Recog 20: 476-482.

38. Xu C, Wang Y (2012) Chemical composition and structure of peritubular and intertubular human dentine revisited. Arch Oral Biol 57: 383-391.

39. Curtis AR, West NX, Su B (2010) Synthesis of nanobioglass and formation of apatite rods to occlude exposed dentine tubules and eliminate hypersensitivity. Acta Biomater 6: 3740-3746.

40. Gedalia I, Brayer L, Kalter N, Richter M, Stabholz A (1978) The effect of fluoride and strontium application on dentine: in vivo and in vitro studies. J Periodontol 49: 269-272.

41. Thuy TT, Nakagaki H, Kato K, Hung PA, Inukai J, et al. (2008) Effect of strontium in combination with fluoride on enamel remineralization in vitro. Arch Oral Biol 53: 1017-1022.

42. Que K, Fu Y, Lin L, Hu D, Zhang YP, et al. (2010) Dentine hypersensitivity reduction of a new toothpaste containing $8.0 \%$ arginine and 1450 ppm fluoride: An 8-week clinical study on Chinese adults. Am J Dent 23: 28A-35A.

43. Lavender SA, Petrou I, Heu R, Stranick MA, Cummins D, et al. (2010) Mode of action studies on a new desensitizing dentifrice containing 8.0\% arginine, a high cleaning calcium carbonate system and $1450 \mathrm{ppm}$ fluoride. Am J Dent 23: 14A-19A. 